\title{
CIENCIAS AGRARIAS
}

\section{Efecto de la Beauveria bassiana (Bals.) sobre el rulo de la yerba mate (Gyropsylla spegazziniana, hemíptera: Psyllidae)}

\author{
Sandra Rodas ${ }^{1}$, Pedro Acuña²
}

\begin{abstract}
Resumen
Introducción: La Yerba Mate (Ilex paraguariensis St. Hil), es un rubro tradicional del Paraguay desarrollado al inicio de forma extractiva de los bosques y con el fin de aumentar la productividad se alteró su hábitat natural y con ello también la incidencia de insectos que se mantenían en equilibrio originalmente; dándose una especial atención a la Gyropsylla spegazziniana, agente causal del rulo de la Yerba Mate. Al no existir un método de control alternativo para esta plaga, se llevó a cabo este trabajo.
\end{abstract}

Objetivo: evaluar la eficacia del entomopatógeno Beauveria bassiana sobre la población de la Gyropsylla spegazziniana. El ensayo se realizó en la finca de un productor ubicado en el distrito de Fram, departamento de Itapúa, entre los meses de febrero y marzo del 2017.

Material y Método: Se utilizó el diseño experimental completamente al azar, con tres tratamientos, un testigo químico y un testigo absoluto, con 8 repeticiones. Cada unidad experimental estuvo conformada por una planta, en total fueron utilizadas cuarenta plantas de yerba. Los tratamientos evaluados fueron testigo absoluto, testigo químico (Imidacloprid 10\% + Betaciflutrin $30 \% 200 \mathrm{cc}$ ) y dosis creciente de la formulación 1,5x10 Exp. 9 conidios/ml de producto 3\% de Beauveria; 500,1000 y 250 cc en 100 I de agua. Las aplicaciones se realizaron con equipo a gas carbónico C02 con pico tipo cónico en horas de la tarde, con humedad relativa superior a $60 \%$, temperatura inferior a $25^{\circ} \mathrm{C}, \mathrm{y}$ viento menor a $10 \mathrm{~km} / \mathrm{h}$, a una distancia de $10 \mathrm{~cm}$ del rulo cerrado. Las ramas tratadas al igual que los testigos después de la aplicación fueron envueltas con tela de organza $(15 \times 30 \mathrm{~cm})$. Luego de 2, 3, 7 y 14 días de realizado los tratamientos, se cortaron las muestras y se trasportaron hasta el laboratorio, donde las ramas fueron mantenidas en recipientes con agua para su posterior lectura bajo estereoscopio. Las variables evaluadas fueron número de ninfas y

\footnotetext{
1. Facultad de Ciencias Agropecuarias y Forestales. Alumna tesista.

2. Docente Tutor.
}

Trabajo Final de carrera presentado para la obtención del título de Ingeniero Agrónomo, Presentado en XXVI JJI Jornada de Jóvenes Investigadores AUGM, en la Universidad Nacional de Cuyo, Mendoza, Argentina.

E-mail: rodas.sandra24@gmail.com

DOI: $10.26885 /$ rcei.foro.2018.14 
adultos muertos, y eficacia de cada tratamiento.

Resultados y Conclusiones: Los resultados del producto químico a comparación del biológico presentó mayor toxicidad y por ende menor selectividad sobre la plaga. El entomopatógeno $B$. bassiana presentó moderada toxicidad sobre ninfa y baja toxicidad sobre adulto del psíllido. La B. bassiana no presentó diferencia entre las dosis evaluadas para el control del psíllido de la yerba mate.

Palabras clave: Beauveria bassiana, rulo, yerba.

\section{REFERENCIAS}

APHA-AWWA-WPCF. (1992). Métodos normalizados para análisis de aguas potables y residuales (17a ed.). Madrid: Ediciones Diaz de Santos S. A.

Araya, C. (2004). Estadística para laboratorista químico. San José: Editorial de la Universidad de Costa Rica. Recuperado de http://www.geocities.ws/ estadistica/archivos/LQ2013.pdf

Box, G (2005) Estadística para Investigadores: Diseño, innovación y descubrimiento. Barcelona: Editorial REVERTE

CEPIS/OPS. (2004). Tratamiento de agua para consumo humano: plantas de filtración rápida. Lima: CEPIS. Recuperado de http://www.bvsde.paho. org/bvsatr/fulltext/tratamiento/manuall/tomol/ma1_tomo1_indice. pdf

UNEP. (2010). Programa de las Naciones Unidas para el medio Ambiente. PNUMA Anuario. Recuperado de http://www.unep.org/yearbook/2010 